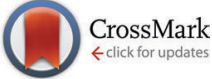

Cite this: Phys. Chem. Chem. Phys., 2016, 18, 16483

Received 16th March 2016, Accepted 23rd May 2016

DOI: $10.1039 / c 6 c p 01781 a$

www.rsc.org/pccp

\title{
NMR absolute shielding scale and nuclear magnetic dipole moment of ${ }^{207} \mathrm{~Pb}$
}

\author{
Bożena Adrjan, ${ }^{a}$ Włodzimierz Makulski, ${ }^{a}$ Karol Jackowski, ${ }^{a}$ Taye B. Demissie, ${ }^{b}$ \\ Kenneth Ruud, ${ }^{\mathrm{b}}$ Andrej Antušek ${ }^{\mathrm{c}}$ and Michat Jaszuński*
}

\begin{abstract}
An absolute shielding scale is proposed for ${ }^{207} \mathrm{~Pb}$ nuclear magnetic resonance (NMR) spectroscopy. It is based on ab initio calculations performed on an isolated tetramethyllead $\mathrm{Pb}\left(\mathrm{CH}_{3}\right)_{4}$ molecule and the assignment of the experimental resonance frequency from the gas-phase NMR spectra of $\mathrm{Pb}\left(\mathrm{CH}_{3}\right)_{4}$, extrapolated to zero density of the buffer gas to obtain the result for an isolated molecule. The computed ${ }^{207} \mathrm{~Pb}$ shielding constant is $10790 \mathrm{ppm}$ for the isolated molecule, leading to a shielding of $10799.7 \mathrm{ppm}$ for liquid $\mathrm{Pb}\left(\mathrm{CH}_{3}\right)_{4}$ which is the accepted reference standard for ${ }^{207} \mathrm{~Pb}$ NMR spectra. The new experimental and theoretical data are used to determine $\mu\left({ }^{207} \mathrm{~Pb}\right)$, the nuclear magnetic dipole moment of ${ }^{207} \mathrm{~Pb}$, by applying the standard relationship between NMR frequencies, shielding constants and nuclear moments of two nuclei in the same external magnetic field. Using the gas-phase ${ }^{207} \mathrm{~Pb}$ and (reference) proton results and the theoretical value of the $\mathrm{Pb}$ shielding in $\mathrm{Pb}\left(\mathrm{CH}_{3}\right)_{4}$, we find $\left.\mu{ }^{207} \mathrm{~Pb}\right)=0.59064 \mu_{\mathrm{N}}$. The analysis of new experimental and theoretical data obtained for the $\mathrm{Pb}^{2+}$ ion in water solutions provides similar values of $\left.\mu{ }^{207} \mathrm{~Pb}\right)$, in the range of $0.59000-0.59131 \mu_{\mathrm{N}}$.
\end{abstract}

\section{Introduction}

The ${ }^{207} \mathrm{~Pb}$ nucleus with nuclear spin number $1 / 2$ is very well suited for applications in nuclear magnetic resonance (NMR) spectroscopy. Its NMR signal at the natural abundance $(22.6 \%)$ is 11.9 times stronger than that obtained by the ${ }^{13} \mathrm{C}$ NMR method. ${ }^{1}$ The range of ${ }^{207} \mathrm{~Pb}$ chemical shifts covers more than $17000 \mathrm{ppm}$, and liquid tetramethyllead, $\mathrm{Pb}\left(\mathrm{CH}_{3}\right)_{4}$, is recommended as the reference standard, ${ }^{2}$ while a small addition of benzene- $\mathrm{d}_{6}$ or toluene- $\mathrm{d}_{8}$ serves for the deuterium lock system. ${ }^{3,4}$ A limited number of chemicals containing lead atoms (mostly inorganic and organometallic compounds) makes ${ }^{207} \mathrm{~Pb}$ NMR spectroscopy less popular, but it is obviously a valuable analytical tool for laboratories involved in research on lead.

The nuclear magnetic dipole moment of the stable isotope of lead, ${ }^{207} \mathrm{~Pb}$, is given in the standard reference tables ${ }^{5}$ as $0.592583(9) \mu_{\mathrm{N}}$, extracted from experimental NMR data ${ }^{6}$ (we shall discuss systematically the maximum projection of the magnetic moment vector on the axis of the external field, determined in NMR, not the magnitude of the vector itself). The same value

\footnotetext{
${ }^{a}$ Laboratory of NMR Spectroscopy, Department of Chemistry, University of Warsaw, Pasteura 1, 02-093 Warsaw, Poland

${ }^{b}$ Centre for Theoretical and Computational Chemistry, Department of Chemistry, UiT The Arctic University of Norway, N-9037 Tromsø, Norway

${ }^{c}$ ATRI, Faculty of Materials Science and Technology in Trnava, Slovak University of Technology in Bratislava, Paulinska 16, 91724 Trnava, Slovak Republic

${ }^{d}$ Institute of Organic Chemistry, Polish Academy of Sciences, 01224 Warszawa,

Kasprzaka 44, Poland. E-mail: michal.jaszunski@icho.edu.pl
}

is given in the recent IUPAC recommendations. ${ }^{7}$ Another tabulated value, derived from the optical pumping experiment, is $0.58219(2) \mu_{\mathrm{N}} \cdot{ }^{8}$ However, both these reference values are more than 40 years old. Recently, the magnetic dipole moment of ${ }^{207} \mathrm{~Pb}$ was studied using different theories for the nuclear structure, the different approximations yielding results in the range of $0.437-0.638 \mu_{\mathrm{N}}{ }^{9}$ and $0.582 \mu_{\mathrm{N}} \cdot{ }^{10}$

We have determined the nuclear magnetic moments of a large number of nuclei from NMR spectra, and shown that significant improvements in the accuracy compared to older data can be obtained by carefully taking chemical shielding effects into account. ${ }^{11}$ This requires the simultaneous experimental measurement of NMR resonance frequencies for the nucleus of interest and a reference nucleus (preferably in the same isolated molecule) in combination with quantum chemical calculations. Together, this allows the corresponding absolute shielding constants to be determined. In this work, we apply this approach to the determination of $\mu\left({ }^{207} \mathrm{~Pb}\right)$ by investigating the properties of tetramethyllead, $\mathrm{Pb}\left(\mathrm{CH}_{3}\right)_{4}$, in the gas phase.

Following our approach, the magnetic dipole moment of a nucleus $\mathrm{X}$ may be determined from NMR data using the equation

$$
\mu_{\mathrm{X}}=\frac{\nu_{\mathrm{X}}}{\nu_{\mathrm{Y}}} \frac{I_{\mathrm{X}}}{I_{\mathrm{Y}}} \frac{\left(1-\sigma_{\mathrm{Y}}\right)}{\left(1-\sigma_{\mathrm{X}}\right)} \mu_{\mathrm{Y}},
$$

where $\nu, \mu$ and $I$ are the resonance frequencies, the nuclear magnetic moments and the spin quantum number of the chosen reference nucleus $\mathrm{Y}$ and nucleus $\mathrm{X}$, respectively. This approach 
was applied already in 1971 to obtain the presently accepted value of $\mu\left({ }^{207} \mathrm{~Pb}\right)$, using deuterium in water as the reference nucleus. ${ }^{6}$ We have repeatedly observed ${ }^{12,13}$ that the most accurate results are obtained when the reference nucleus $\mathrm{Y}$ is a hydrogen nucleus in the same molecule as nucleus X. Moreover, in contrast to the 1971 work (and similar early studies for other nuclei) we can now calculate the shielding of the nucleus of interest from $a b$ initio methods rather than estimate it, as has been done in the past. We shall also use an inverted form of eqn (1) (see e.g. ref. 14)

$$
\sigma_{\mathrm{Pb}}=1-\frac{\nu_{\mathrm{Pb}}}{\nu_{\mathrm{Y}}} \frac{\mu_{\mathrm{Y}}}{\mu_{\mathrm{Pb}}} \frac{I_{\mathrm{Pb}}}{I_{\mathrm{Y}}}\left(1-\sigma_{\mathrm{Y}}\right)
$$

primarily to illustrate how minor variations in the estimated nuclear magnetic moment may affect $\sigma(\mathrm{Pb})$.

\section{NMR experiment}

\subsection{Gaseous $\mathrm{Pb}\left(\mathrm{CH}_{3}\right)_{4}$}

Tetramethyllead was studied by NMR, measuring the ${ }^{207} \mathrm{~Pb}$, ${ }^{13} \mathrm{C}$ and ${ }^{1} \mathrm{H}$ resonance frequencies in the gas phase. A small amount of tetramethyllead (in each sample $\approx 0.02 \mathrm{~mol} \mathrm{~L}^{-1}, p=0.2 \mathrm{bar}$ ) was mixed with two gases, $\mathrm{SF}_{6}(99.8+\%$ from Aldrich) and - in a separate series of measurements - with Xe $(99.99 \%$ from Messer Griesheim). In different samples, the density of these gaseous solvents varied from 0.44 to $1.4 \mathrm{~mol} \mathrm{~L}^{-1}$, and the pressure was 11-34 bar.

In general, for a binary mixture of gases $\mathrm{A}$ and $\mathrm{B}$, a linear approximation for the virial expansion of $\nu^{\mathrm{A}}(\mathrm{X})$, the frequency of the $\mathrm{X}$ nucleus in compound $\mathrm{A}$, can be written as (see e.g. ref. 15)

$$
\nu^{\mathrm{A}}(\mathrm{X})=\nu_{0}^{\mathrm{A}}(\mathrm{X})+\nu_{1}^{\mathrm{AA}}(\mathrm{X}) \rho_{\mathrm{A}}+\nu_{1}^{\mathrm{AB}}(\mathrm{X}) \rho_{\mathrm{B}}
$$

where $\nu_{0}^{\mathrm{A}}(\mathrm{X})$ represents the resonance frequency in the isolated molecule $\mathrm{A}$, the coefficients $\nu_{1}^{\mathrm{AA}}(\mathrm{X})$ and $\nu_{1}^{\mathrm{AB}}(\mathrm{X})$ describe the effects due to binary $\mathrm{A}-\mathrm{A}$ and $\mathrm{A}-\mathrm{B}$ collisions, and $\rho_{\mathrm{A}}$ and $\rho_{\mathrm{B}}$ are the densities of $\mathrm{A}$ and $\mathrm{B}$ - in our case $\mathrm{Pb}\left(\mathrm{CH}_{3}\right)_{4}$ and $\mathrm{SF}_{6}$ or Xe, respectively. We use in all the experiments very small amounts of $\mathrm{Pb}\left(\mathrm{CH}_{3}\right)_{4}$, therefore the $\nu_{1}^{\mathrm{AA}}(\mathrm{X}) \rho_{\mathrm{A}}$ term can be systematically neglected, and to estimate $\nu_{0}^{\mathrm{A}}(\mathrm{X})$ we can apply a simplified equation

$$
\nu^{\mathrm{A}}(\mathrm{X})=\nu_{0}^{\mathrm{A}}(\mathrm{X})+\nu_{1}^{\mathrm{AB}}(\mathrm{X}) \rho_{\mathrm{B}}
$$

A successive completion of two similar sets of experiments, but with a different gas solvent $\mathrm{B}$, permits the determination of $\nu_{0}^{\mathrm{A}}(\mathrm{X})$ with high accuracy. This approach was previously verified in numerous NMR experiments (see for instance Fig. 2 in ref. 16).

The experimental frequencies were linearly extrapolated using eqn (4) to the zero-density limit, allowing the ${ }^{207} \mathrm{~Pb},{ }^{13} \mathrm{C}$ and ${ }^{1} \mathrm{H}$ resonance frequencies for an isolated $\mathrm{Pb}\left(\mathrm{CH}_{3}\right)_{4}$ molecule to be determined (see Fig. 1 for the ${ }^{207} \mathrm{~Pb}$ results). NMR gas samples were prepared according to our standard method described in ref. 17. Liquid benzene- $d_{6}$ (Aldrich, 99.6\% D) was applied as the solvent for the deuterium lock system and the secondary reference standard of ${ }^{1} \mathrm{H}$ and ${ }^{13} \mathrm{C}$ shielding $\left(\nu_{\mathrm{D}}=76.8464017 \mathrm{MHz}\right.$ and $\left.\sigma_{\mathrm{D}}=26.441 \mathrm{ppm}^{14}\right)$. All the NMR measurements of resonance frequencies were carried out on a Varian-INOVA-500 spectrometer with a switchable probehead (50-500 $\mathrm{MHz}$ Varian) at $300 \mathrm{~K}$. The temperature inside the NMR tubes was controlled

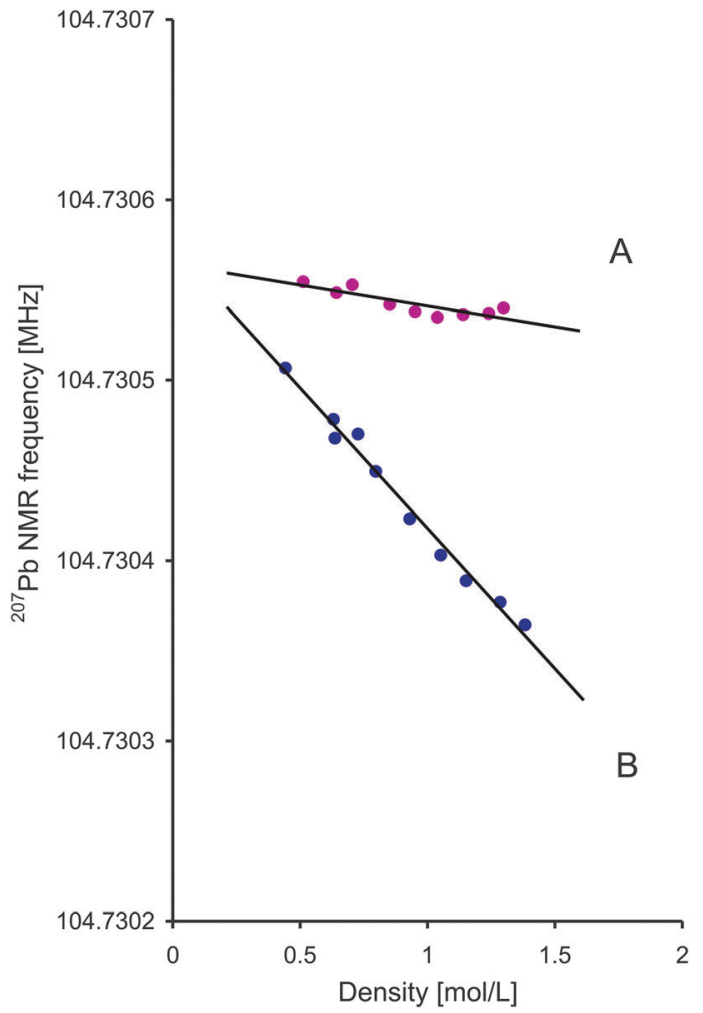

Fig. 1 A small amount of $\mathrm{Pb}\left(\mathrm{CH}_{3}\right)_{4}$ mixed with gaseous solvents: (A) extrapolation to zero density of $\mathrm{SF}_{6}: \nu=-0.00002316 \rho+104.730564$ and (B) extrapolation to zero density of $\mathrm{Xe}: \nu=-0.00015586 \rho+104.730574$.

Table 1 Extrapolated experimental gas-phase results for $\mathrm{Pb}\left(\mathrm{CH}_{3}\right)_{4}$

\begin{tabular}{llll}
\hline Nucleus & Perturber & $\nu_{0} / \mathrm{MHz}$ & $\sigma_{0} / \mathrm{ppm}$ \\
\hline${ }^{1} \mathrm{H}$ & $\mathrm{Xe}$ & $500.6062980(3)$ & 30.075 \\
& $\mathrm{SF}_{6}$ & $500.6062972(4)$ & 30.076 \\
& Average & $500.6062976(4)$ & $30.075(2)$ \\
${ }^{13} \mathrm{C}$ & $\mathrm{Xe}$ & $125.8761536(15)$ & 194.09 \\
& $\mathrm{SF}_{6}$ & $125.8761563(18)$ & 194.07 \\
& Average & $125.876155(2)$ & $194.08(2)$ \\
${ }^{207} \mathrm{~Pb}$ & $\mathrm{Xe}$ & $104.7305736(60)$ & \\
& $\mathrm{SF}_{6}$ & $104.7305642(75)$ & \\
& Average $^{a}$ For $80 \% \mathrm{~Pb}\left(\mathrm{CH}_{3}\right)_{4}$ in toluene $\nu=104.729551 \mathrm{MHz}$. & \\
\hline
\end{tabular}

with pure liquid methanol. The ${ }^{1} \mathrm{H}$ and ${ }^{207} \mathrm{~Pb}$ measurements were performed using standard parameters. The decoupled INEPT sequence, optimized for the ${ }^{1} J\left({ }^{13} \mathrm{C},{ }^{1} \mathrm{H}\right)=135.0 \mathrm{~Hz}$ constant and proton relaxation times, was applied to increase the strength of the ${ }^{13} \mathrm{C}$ signals. The absolute experimental ${ }^{1} \mathrm{H}$ and ${ }^{13} \mathrm{C}$ shielding constants were obtained following the approach described in ref. 14. The final results, obtained using $\mathrm{Xe}$ and $\mathrm{SF}_{6}$, as well as the averaged values which we use in the following, are collected in Table 1.

\section{2 $\mathrm{Pb}^{2+}$ ions in water solutions}

Aqueous solutions of lead(II) perchlorate $\left(\mathrm{Pb}\left(\mathrm{ClO}_{4}\right)_{2}\right.$, Sigma-Aldrich, $98 \%)$ and lead(II) nitrate $\left(\mathrm{Pb}\left(\mathrm{NO}_{3}\right)_{2}, \mathrm{POCH}, 99 \%\right)$ were prepared 
using double-distilled water (conductivity $<0.056 \mathrm{mS} \mathrm{cm}^{-1}$ ) on the same days as the NMR measurements were carried out. The solutions (conc. 0.02-1.5 M) in $4 \mathrm{~mm}$ o.d. glass tubes (Wilmad, 406PP) were placed in standard $5 \mathrm{~mm}$ o.d. NMR tubes (Wilmad, 528PP) with benzene- $\mathrm{d}_{6}$ in the annular space for a deuterium lock system. ${ }^{207} \mathrm{~Pb}$ NMR spectra were recorded at $298 \mathrm{~K}$ using a Bruker AVANCE III HD $500 \mathrm{MHz}$ spectrometer with the $5 \mathrm{~mm}$ CPPBBO BB probehead. The observed ${ }^{207} \mathrm{~Pb}$ frequency of the Bruker spectrometer was carefully verified with the use of gaseous and reference samples; we obtained a difference of $-0.0847151 \mathrm{MHz}$ relative to our Varian spectrometer. This correction was added to all the experimental points for both aqueous solutions, $\mathrm{Pb}\left(\mathrm{ClO}_{4}\right)_{2}$ and $\mathrm{Pb}\left(\mathrm{NO}_{3}\right)_{2}$.

The reference nucleus for the evaluation of the $\mathrm{Pb}$ magnetic moment in this $\mathrm{Pb}^{2+}$ experiment is the deuteron in liquid $\mathrm{C}_{6} \mathrm{D}_{6}$, the deuteron magnetic moment is $0.8574382308 \mu_{\mathrm{N}}{ }^{18}$.

As shown in Fig. 2, in each solution the $\mathrm{Pb}$ frequency can be extrapolated to zero concentration applying a second-order polynomial to fit the results in the $0-0.1 \mathrm{~mol} \mathrm{~L}^{-1}$ concentration range $\left(r^{2}>0.97\right.$ for both curves). We note that for $\mathrm{Pb}\left(\mathrm{NO}_{3}\right)_{2} \mathrm{a}$ similar concentration dependence has been observed previously. ${ }^{19}$ Both experiments, that is $\mathrm{Pb}\left(\mathrm{ClO}_{4}\right)_{2}$ and $\mathrm{Pb}\left(\mathrm{NO}_{3}\right)_{2}$, give similar (although not identical) values of the frequency of the hydrated $\mathrm{Pb}^{2+}$ ion, 104.4284576 and $104.4280673 \mathrm{MHz}$, respectively. The average value, $104.4282624 \mathrm{MHz}$, is our best estimate of this

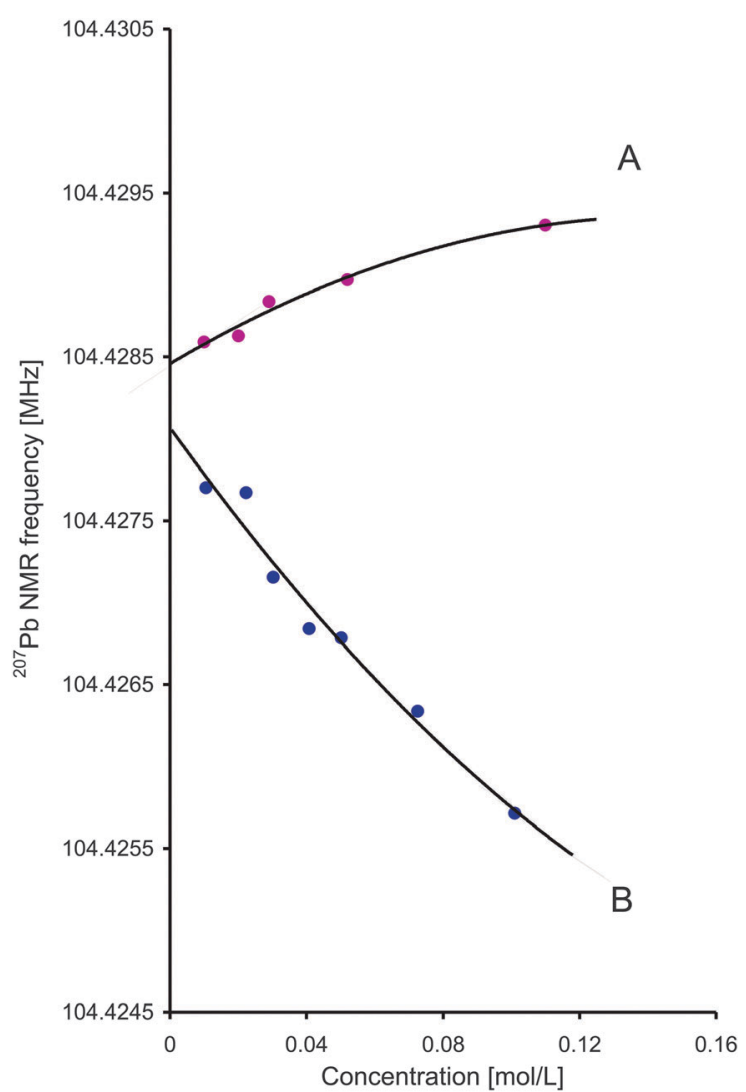

Fig. 2 (A) Upper curve: $\mathrm{Pb}\left(\mathrm{ClO}_{4}\right)_{2}$ in water; $\nu=-0.0425043 \rho^{2}+0.0123594 \rho+$ 104.4284576; (B) lower curve: $\mathrm{Pb}\left(\mathrm{NO}_{3}\right)_{2}$ in water; $\nu=0.0591139 \rho^{2}-$ $0.0290864 \rho+104.4280673$.

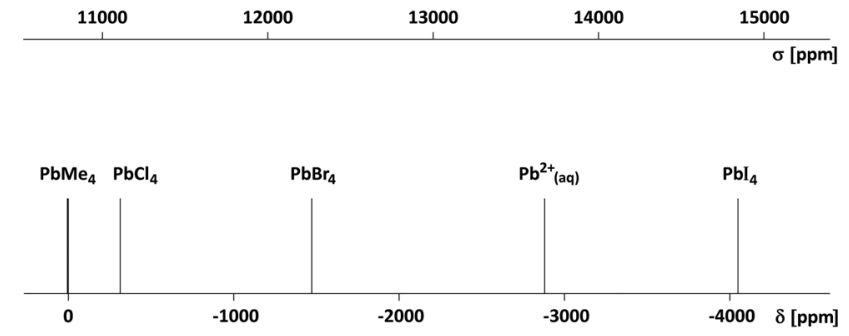

Fig. $3{ }^{207} \mathrm{~Pb}$ NMR signals of some simple chemical compounds on the scale of shielding $(\sigma)$ and the chemical shift $(\delta)$. The chemical shift of an isolated $\mathrm{Pb}\left(\mathrm{CH}_{3}\right)_{4}$ molecule is $\delta_{0}=+9.72 \mathrm{ppm}$.

frequency and gives $-2876.8 \mathrm{ppm}$ as the ${ }^{207} \mathrm{~Pb}$ chemical shift of the hydrated $\mathrm{Pb}^{2+}$ ion. For comparison, the ${ }^{207} \mathrm{~Pb}$ chemical shift of aqueous $\mathrm{Pb}\left(\mathrm{NO}_{3}\right)_{2}$ solution was earlier given as $-2961 \mathrm{ppm}^{3}$, or $-2965.7 \mathrm{ppm}$ (for $1.10 \mathrm{~m}$ solution). ${ }^{19}$

A simple check using eqn (1) shows that an error of $0.01 \mathrm{MHz}$ in the $\mathrm{Pb}$ frequency leads to a $0.0001 \mu_{\mathrm{N}}$ change in $\mu\left({ }^{207} \mathrm{~Pb}\right)$. Thus, the $\approx 0.0004 \mathrm{MHz}$ difference between the extrapolated results for two solutions is negligible, similar to other small effects in our experiment. In particular, two orders of magnitude larger changes of the final $\mathrm{Pb}$ magnetic moment arise from variations in the computed $\mathrm{Pb}$ shielding constant (see Section 4.2).

A chart illustrating the relative positions of various ${ }^{207} \mathrm{~Pb}$ signals on the new shielding scale and the corresponding NMR chemical shifts is given in Fig. 3. Our experiments have shown that the reference nucleus $\left(\mathrm{Pb}\left(\mathrm{CH}_{3}\right)_{4}\right.$ liquid in toluene) is $9.72 \mathrm{ppm}$ more shielded than in the isolated $\mathrm{Pb}\left(\mathrm{CH}_{3}\right)_{4}$ molecule when the reference solution is observed in a cylindrical sample tube placed in a superconducting magnet. As mentioned above, the chemical shift of the hydrated $\mathrm{Pb}^{2+}(\mathrm{aq})$ ion is $-2876.8 \mathrm{ppm}$; the ${ }^{207} \mathrm{~Pb}$ chemical shifts of some other simple compounds have been taken from ref. 20 .

\section{Calculation of the shielding constants}

\subsection{Nonrelativistic ab initio calculations}

We shall limit our discussion to the isotropic shielding constants as there are no experimental data for any of the tensor elements. Unless otherwise stated, all Hartree-Fock (HF) and coupled-cluster singlesand-doubles (CCSD) nonrelativistic results have been obtained using a point nucleus model. The nonrelativistic density-functional theory (DFT) values have also been calculated using a point nucleus, whereas in the relativistic Dirac-Kohn-Sham (DKS) calculations we use a Gaussian nucleus model. ${ }^{21}$ We have used the experimental geometry of $\mathrm{Pb}\left(\mathrm{CH}_{3}\right)_{4}$ taken from ref. 22 .

We begin with an analysis of the nonrelativistic results. We use the coupled-cluster analytic second derivative methods developed by Gauss, Stanton and coworkers ${ }^{23-26}$ to determine the shielding constants. The nonrelativistic results were calculated using the CFOUR $^{27}$ program package, which uses gauge-including atomic orbitals (GIAOs ${ }^{28,29}$ ) to improve basis set convergence and obtain gauge-origin independent results. 
Table $2 A b$ initio CCSD and HF shielding constants ${ }^{a}$

\begin{tabular}{|c|c|c|c|}
\hline & $\mathrm{Pb}$ & $\mathrm{C}$ & $\mathrm{H}$ \\
\hline \multicolumn{4}{|c|}{ unc-dyall.cvdz } \\
\hline CCSD & 5934.0 & 218.92 & 32.833 \\
\hline $\mathrm{HF}$ & 6066.7 & 218.75 & 33.138 \\
\hline CGO, CCSD & 5998.5 & 222.22 & 30.934 \\
\hline $\mathrm{CGO}, \mathrm{HF}$ & 6114.8 & 222.99 & 31.191 \\
\hline \multicolumn{4}{|l|}{ unc-dyall.cvtz } \\
\hline $\mathrm{HF}$ & 6053.1 & 217.19 & 32.645 \\
\hline \multicolumn{4}{|c|}{ unc-dyall.cvqz } \\
\hline $\mathrm{HF}$ & 6053.6 & 216.96 & 32.510 \\
\hline \multicolumn{4}{|c|}{ Jorge, unc-ADZP } \\
\hline CCSD & 6200.9 & 220.29 & 32.756 \\
\hline $\mathrm{HF}$ & 6315.0 & 219.68 & 32.941 \\
\hline
\end{tabular}

The basis set dependence of the results was investigated at the HF level using the uncontracted version of Dyall's relativistic core-valence double- $\zeta$ (cvdz), triple- $\zeta$ (cvtz) and quadruple- $\zeta$ (cvqz) basis sets. ${ }^{30-33}$ For $\mathrm{Pb}\left(\mathrm{CH}_{3}\right)_{4}$, these uncontracted basis sets contain 457, 766 and 1224 functions, respectively. Even though the basis set dependence is found to be weak (see Table 2), the cvqz basis set was used in the final DFT calculations and analyses. The larger basis sets cannot be used at the CCSD level, and we therefore also report the results obtained with the uncontracted Jorge's ADZP basis set, ${ }^{34}$ which has 348 basis functions.

\subsection{Relativistic density-functional theory calculations}

The four-component relativistic DFT calculations were performed employing a development version of the program package ReSpect. ${ }^{35}$ We used the restricted magnetic balance scheme for calculations of the NMR shielding constants ${ }^{36,37}$ and the restricted kinetic balance scheme for the spin-rotation constants. ${ }^{38}$ The BP86, ${ }^{39,40}$ $\mathrm{PBE}^{41}$ and $\mathrm{B}^{4} \mathrm{LYP}^{42-44}$ exchange-correlation functionals were used in these DFT calculations.

The BP86 and PBE absolute shielding constants were obtained using the GIAO approach. As shown in Table 3 , the relativistic DKS/BP86 results are practically converged when extending the basis set. Absolute shielding constants obtained using the largest basis set for the BP86, PBE and B3LYP functionals are also reported for comparison in Table 4. The B3LYP results and the spin-rotation constants were obtained using the common

Table 3 Basis set dependence of DKS/BP86 absolute shielding constants $\left(\sigma\right.$, in ppm) in $\mathrm{Pb}\left(\mathrm{CH}_{3}\right)_{4}{ }^{a}$

\begin{tabular}{llll}
\hline & $\mathrm{Pb}$ & $\mathrm{C}$ & $\mathrm{H}$ \\
\hline BP86 & & & \\
unc-dyall.cvdz & 10247.4 & 190.22 & 31.410 \\
unc-dyall.cvtz & 10210.2 & 189.68 & 30.876 \\
unc-dyall.cvqz $^{b}$ & 10200.9 & 189.58 & 30.723 \\
unc-dyall.cvqz $^{b}$ & 10256.3 & 189.56 & 30.526
\end{tabular}

${ }^{a}$ Shielding constants calculated employing the GIAO approach unless stated otherwise. ${ }^{b}$ Shielding constants calculated employing the CGO approach.
Table 4 Nonrelativistic and four-component relativistic absolute shielding constants $(\sigma$, in ppm) and the relativistic corrections $(\Delta($ rel $))$ calculated using DFT/unc-dyall.cvqz ${ }^{a}$

\begin{tabular}{lrrr}
\hline & \multicolumn{1}{c}{$\mathrm{Pb}$} & $\mathrm{C}$ & $\mathrm{H}$ \\
\hline BP86 & & & \\
NR & 5331.7 & 201.26 & 31.959 \\
DKS & 10200.9 & 189.58 & 30.723 \\
$\Delta$ (rel) & 4869.2 & -11.68 & -1.238 \\
& & & \\
PBE & & & 31.674 \\
NR & 5360.0 & 201.98 & 30.699 \\
DKS & 10223.4 & 190.18 & -0.975 \\
$\Delta$ (rel) & 4863.4 & -11.80 & \\
B3LYP & & & 31.864 \\
NR & & & 30.732 \\
DKS & 5466.3 & 202.80 & -1.132 \\
$\Delta$ (rel) & 10649.7 & 190.77 &
\end{tabular}

${ }^{a}$ Shielding constants calculated employing the GIAO approach (BP86 and PBE) and the CGO approach (B3LYP). Point nuclei at NR, the Gaussian model of the nuclei at the DKS level.

gauge-origin (CGO) approach, where the gauge origin was placed at the center of nuclear mass. ${ }^{38}$

The relativistic corrections, $\Delta(\mathrm{rel})$, are estimated as the difference between the relativistic (DKS) and the nonrelativistic (NR) values obtained applying the same exchange-correlation functional and the cvqz basis sets. The Gaussian nucleus model was used at the DKS level, because we have observed that the differences in the relativistic Pb shielding constants computed applying Gaussian and point nucleus are significant - the DKS values of $\sigma(\mathrm{Pb})$ determined using the Gaussian nuclear model are approximately $350 \mathrm{ppm}$ lower than those obtained for a point nucleus. At the NR level, this difference is less than $1 \mathrm{ppm}$, whereas for $\mathrm{C}$ and $\mathrm{H}$ nuclei the differences are below $1 \mathrm{ppm}$ for both levels of theory.

\section{Results and discussion}

\section{1 $\mathrm{Pb}\left(\mathrm{CH}_{3}\right)_{4}$}

The only previous theoretical estimate of $\sigma(\mathrm{Pb})$ in $\mathrm{Pb}\left(\mathrm{CH}_{3}\right)_{4}$, $14475.1 \pm 500.7 \mathrm{ppm}$, was obtained by applying a crude approximation relating the $\mathrm{Sn}$ and $\mathrm{Pb}$ shielding constants. ${ }^{20}$

From the results reported in Table 2 we see that the uncorrelated nonrelativistic results obtained with the unc-dyall.cvqz basis set are close to the basis set limit, as the cvtz and cvqz shielding constants differ by less than $1 \mathrm{ppm}$ for all nuclei at the HF level. As shown in Table 3, at the DKS/BP86/unc-dyall.cvqz level this difference is also smaller than $1 \mathrm{ppm}$ for the $\mathrm{C}$ and $\mathrm{H}$ nuclei, and smaller than $10 \mathrm{ppm}$ for $\sigma(\mathrm{Pb})$. Moreover, the GIAO and CGO shielding constants are practically identical for the $\mathrm{C}$ and $\mathrm{H}$ nuclei, whereas $\sigma(\mathrm{Pb})$ computed with GIAOs is about $60 \mathrm{ppm}(0.6 \%)$ smaller than that computed using the CGO approach. Very similar results, showing satisfactory convergence, were obtained with the PBE functional.

To estimate the dependence of the shielding constants on molecular geometry, calculations were performed for two additional structures, determined by contracting and stretching all 
Table 5 Total shielding constants in $\mathrm{Pb}\left(\mathrm{CH}_{3}\right)_{4}$ - sums of contributions (in ppm)

\begin{tabular}{lrrr}
\hline & \multicolumn{1}{c}{$\mathrm{Pb}$} & \multicolumn{1}{l}{$\mathrm{C}$} & \multicolumn{1}{c}{$\mathrm{H}$} \\
\hline HF, unc-dyall.cvqz & 6053.6 & 216.96 & 32.51 \\
$\Delta$ CCSD, unc-dyall.cvdz & -132.7 & 0.17 & -0.31 \\
$\Delta(\mathrm{rel})$, BP86 & 4869.2 & -11.68 & -1.24 \\
Total & 10790.1 & 205.45 & 30.97 \\
& & & \\
$\Delta(\mathrm{rel})$, PBE & 4863.4 & -11.8 & -0.98 \\
Total & 10784.3 & 205.33 & 31.23 \\
& & & \\
$\Delta(\mathrm{rel})$, B3LYP & 5183.4 & -12.03 & -1.13 \\
Total & 11104.3 & 205.10 & 31.07 \\
& & & \\
Experiment & - & 194.08 & 30.07 \\
\hline
\end{tabular}

the bonds in the experimental structure by $1 \%$. The results obtained at the four-component BP86/unc-dyall.cvqz level indicate the very weak dependence of $\sigma(\mathrm{Pb})$ on the geometry, the values for these contracted or stretched geometries differing at most by $35 \mathrm{ppm}$ from the value obtained at the experimental geometry; this is negligible on the scale of the lead shielding. In contrast, the $\mathrm{C}$ and $\mathrm{H}$ shielding constants vary significantly, by $\approx 5 \mathrm{ppm}$ and $\approx 0.4 \mathrm{ppm}$, and this geometry dependence may contribute to the difference observed between our best results and experimental data (see Table 5). Since we are primarily interested in the computed shielding of ${ }^{207} \mathrm{~Pb}$, we have not attempted to perform a more detailed study of the geometry dependence of the shielding constants.

Finally, we can determine from eqn (1) the nuclear magnetic dipole moment of ${ }^{207} \mathrm{~Pb}$. Using the resonance frequencies and $\sigma_{\mathrm{H}}$ values given in Table $1, \mu\left({ }^{1} \mathrm{H}\right)=2.792847356 \mu_{\mathrm{N}}{ }^{18}$ and $\sigma_{\mathrm{Pb}}=10790 \mathrm{ppm}$, we obtain $\mu\left({ }^{207} \mathrm{~Pb}\right)=0.59064 \mu_{\mathrm{N}}$. Assuming rather conservative error bars for the computed $\mathrm{Pb}$ shielding constant of $\pm 800 \mathrm{ppm}$, we find that $\mu\left({ }^{207} \mathrm{~Pb}\right)$ is in the range of 0.59016-0.59112 $\mu_{\mathrm{N}}$ (note that in ref. 13 we used erroneous input data to estimate $\left.\mu\left({ }^{207} \mathrm{~Pb}\right)\right)$. For comparison, using the experimental values of the nuclear magnetic moment of 0.592583 and $0.58219 \mu_{\mathrm{N}}$ leads (from eqn (2)) to $\sigma(\mathrm{Pb})$ values of 14034 and $-3576 \mathrm{ppm}$, respectively. Consequently, the latter experimental value of $\mu\left({ }^{207} \mathrm{~Pb}\right)$ can be excluded.

Despite the lack of experimental data, we have also computed the spin-rotation constants in $\mathrm{Pb}\left(\mathrm{CH}_{3}\right)_{4}$, at different levels of approximation. At the relativistic BP86/unc-dyall.cvqz level of theory, we obtain for $\mathrm{Pb}, \mathrm{C}$ and $\mathrm{H}-19.778,-0.240$ and $0.140 \mathrm{kHz}$, respectively. The relativistic contribution is significant for $\mathrm{Pb}$, $-6.550 \mathrm{kHz}$, and very small for the $\mathrm{C}$ and $\mathrm{H}$ nuclei. The PBE results are practically identical to the BP86 data, whereas for B3LYP we find for $\mathrm{Pb}-18.376 \mathrm{kHz}$. The nuclear $g$-factors used in these calculations were taken from ref. 7.

\section{2 $\mathrm{Pb}^{2+}$ ions in water solutions}

The standard value of the lead magnetic moment has been determined from studies of the $\mathrm{Pb}^{2+}$ ion in a water solution, ${ }^{6}$ and we have therefore also reproduced the NMR experiment and attempted to compute the corresponding shielding constant. Unfortunately, in the literature there are a variety of different data for the solvation shell structure of the $\mathrm{Pb}^{2+}$ ion in aqueous solution (see e.g. ref. 45-47). EXAFS experiments indicate a hemidirected, six-coordinated structure with an average $\mathrm{Pb}-\mathrm{O}$ distance of 2.54(1) $\AA^{46}$ In contrast, the most recent molecular dynamics study of aqueous lead ions predicts a coordination number between seven and ten, with a strong predominance of an eightcoordination structure, followed by a nine-coordination structure. ${ }^{47}$ It appears that the observed structure of the $\mathrm{Pb}^{2+}$-water complexes may strongly depend on the timescale of the experiment. Thus, in order to estimate the NMR shielding constant for $\mathrm{Pb}^{2+}$ in aqueous solution, we have considered the $\mathrm{Pb}^{2+}$-water clusters with coordination number $n_{\mathrm{c}}=6,7,8,9$.

The geometries of the complexes were optimized using secondorder Møller-Plesset perturbation theory (MP2) using a 60-electron effective core potential cc-pVQZ-PP for $\mathrm{Pb}^{48,49}$ and the corresponding Dunning's cc-pVQZ basis set ${ }^{50}$ for $\mathrm{O}$ and $\mathrm{H}$, keeping the oxygen core electrons frozen. NWChem was used for these structure optimizations. ${ }^{51}$ The optimized six- and seven-coordinated $\mathrm{Pb}^{2+}$-water clusters were found to be hemi-directed with an average $\mathrm{Pb}-\mathrm{O}$ distance of $2.55 \AA$ and $2.59 \AA$, respectively. The eightcoordinated cluster had a square-antiprism geometry and the nine-coordinated cluster a tricapped trigonal prism structure, and the average $\mathrm{Pb}-\mathrm{O}$ distances were found to be $2.63 \AA$ and $2.67 \AA$, respectively.

NMR shielding constants were first calculated for a bare $\mathrm{Pb}^{2+}$ ion and for the optimized $\mathrm{Pb}^{2+}$-water clusters at the nonrelativistic HF level of theory using a large GIAO basis set created by combining the uncontracted ANO-RCC basis ${ }^{52}$ for lead and Dunning's cc-pVTZ basis sets for hydrogen and oxygen, which is expected to give shieldings close to the basis set limit. ${ }^{53}$ Electron correlation effects were computed using a small double- $\zeta$ basis set (Jorge DZP for Pb and cc-pVDZ for $\mathrm{O}$ and $\mathrm{H})$. The relativistic corrections were calculated at the DFT/BP86 level in the same manner as the relativistic corrections for $\mathrm{Pb}\left(\mathrm{CH}_{3}\right)_{4}$. The different contributions as well as the total estimated shielding constant at the optimized geometries are collected in Table 6.

We also performed some calculations for solvated $\mathrm{Pb}^{2+}$-water clusters in which additional water molecules have been placed

Table 6 Shielding constants of the bare $\mathrm{Pb}^{2+}$ ion and the $\mathrm{Pb}^{2+}$ ion in water clusters with coordination numbers $n_{c}=6,7,8$ and 9

\begin{tabular}{lrrrrr}
\hline$n_{\mathrm{c}}$ & \multicolumn{1}{l}{6} & \multicolumn{1}{c}{7} & \multicolumn{1}{c}{8} \\
\hline $\mathrm{NR}-H F^{a}$ & 10049.1 & 8752.9 & 8952.0 & 9216.4 & 9283.0 \\
NR-HF $^{b}$ & 10023.8 & 9235.8 & 9402.0 & 9613.9 & 9610.0 \\
NR-CCSD $^{b}$ & 10023.1 & 9203.3 & 9344.1 & 9514.3 & 9523.5 \\
$\Delta$ (corr) $^{c}$ & -0.7 & -32.5 & -57.9 & -99.6 & -86.5 \\
NR-BP86 $^{d}$ & 10049.5 & 8105.0 & 8243.6 & 8449.9 & 8569.9 \\
DKS-BP86 $^{e}$ & 17130.5 & 12945.2 & 13402.5 & 14070.6 & 14336.5 \\
$\Delta(\mathrm{rel})^{f}$ & 7081.0 & 4840.2 & 5158.9 & 5620.7 & 5766.6 \\
Total $^{g}$ & 17130.1 & 13560.6 & 14053.0 & 14737.5 & 14963.1
\end{tabular}

${ }^{a}$ Uncontracted ANO-RCC basis set for $\mathrm{Pb}$; cc-pVTZ for $\mathrm{O}$ and $\mathrm{H}$. ${ }^{b}$ Smaller basis set: DZV for Pb; cc-pVDZ for $\mathrm{O}$ and H. ${ }^{c}$ Nonrelativistic correlation correction: NR-CCSD - NR-HF, smaller basis set. ${ }^{d}$ Nonrelativistic DFT/BP86 with the unc-dyall.cvqz basis set. ${ }^{e}$ Relativistic DKS/BP86 with the unc-dyall.cvqz basis set. ${ }^{f}$ Relativistic correction. ${ }^{g}$ Nonrelativistic HF + correlation correction + relativistic correction. 
Table 7 Comparison of ${ }^{207} \mathrm{~Pb}$ nuclear magnetic dipole moment values

\begin{tabular}{|c|c|c|c|}
\hline$\mu\left({ }^{207} \mathrm{~Pb}\right)\left[\mu_{\mathrm{N}}\right]$, source & Reference nucleus, $\nu_{\text {ref }}[\mathrm{MHz}], \sigma_{\text {ref }}[\mathrm{ppm}]$ & $\nu_{\mathrm{Pb}}[\mathrm{MHz}]$ & $\sigma(\mathrm{Pb})[\mathrm{ppm}]$ \\
\hline $\begin{array}{l}0.59059-0.59143 \\
\mathrm{NMR}, \mathrm{Pb}^{2+} \text { aqueous ion }\end{array}$ & $\begin{array}{l}\mathrm{D} \text { in } \mathrm{C}_{6} \mathrm{D}_{6} \\
76.84640167 \\
26.441\end{array}$ & $104.428262(200)$ & $\begin{array}{l}{[13560.6-14963.1]^{a}} \\
13657 \pm 600^{b}\end{array}$ \\
\hline $\begin{array}{l}0.592583(9),,^{5 c} \\
\text { NMR, old value }^{6}\end{array}$ & $\mathrm{D}$ in $\mathrm{D}_{2} \mathrm{O}$ & & 17810 \\
\hline $\begin{array}{l}0.58219(2)^{5} \\
\text { Optical pumping }\end{array}$ & & & \\
\hline
\end{tabular}

in the second solvation shell. These results indicate that the final theoretical prediction of the $\mathrm{Pb}^{2+}$ shielding in aqueous solution might be lower than our estimates for the first solvation shell structures by several hundred ppm.

The nonrelativistic values of the chemical shift induced by the interaction with water in the $\mathrm{Pb}^{2+}$-water clusters studied here are smaller than those calculated for other ion-water clusters (see e.g. ref. 53). This shift is enhanced by the relativistic effects, reaching $21 \%$ and $14 \%$ of the bare ion shielding for the six- and eight-coordinated clusters, respectively. The magnitude of the correlation effects, calculated using a small basis set, indicates that electron correlation is not very important for these clusters and thus does not significantly affect the accuracy of the chemical shielding of the water-solvated lead ion.

The $\mathrm{Pb}\left(\mathrm{CH}_{3}\right)_{4}$ calculations and the NMR experimental investigation, which determined the chemical shift between $\mathrm{Pb}\left(\mathrm{CH}_{3}\right)_{4}$ and the aqueous $\mathrm{Pb}^{2+}$ ion to be $-2876.8 \mathrm{ppm}$, lead to a shielding of aqueous $\mathrm{Pb}^{2+}$ of $13657.2 \mathrm{ppm}$. This value is close to the computed shielding of the six-coordinated $\mathrm{Pb}^{2+}$ ion cluster, $13560.6 \mathrm{ppm}$. It appears that in the NMR experiment, the observed shielding is in agreement with the EXAFS prediction ${ }^{46}$ that the lead ion will have a six-coordinated solvation structure.

We can now estimate the magnetic dipole moment of ${ }^{207} \mathrm{~Pb}$ using the $\mathrm{Pb}^{2+}$ ion experimental data, with deuterium in $\mathrm{C}_{6} \mathrm{D}_{6}$ as the reference (see Table 7). However, in this case the computed lead shielding constants are much less reliable than for $\mathrm{Pb}\left(\mathrm{CH}_{3}\right)_{4}$. We can apply eqn (1) and the $\mathrm{Pb}^{2+}$ shielding constant determined via the experimental chemical shift, $13657.2 \mathrm{ppm}$, to obtain $\mu\left({ }^{207} \mathrm{~Pb}\right)=0.59065 \mu_{\mathrm{N}}$. However, this is not an independent result for $\mu\left({ }^{207} \mathrm{~Pb}\right)$, but instead it indicates the consistency and accuracy of the experimental data for $\mathrm{Pb}\left(\mathrm{CH}_{3}\right)_{4}$ and $\mathrm{Pb}^{2+}$ ions. Assuming that the error bars of this $\mathrm{Pb}^{2+}$ shielding constant are $\pm 1100 \mathrm{ppm}$, which means encompassing the new, independently computed 6-8 solvated cluster results, we find that $\mu\left({ }^{207} \mathrm{~Pb}\right)$ is in the range of $0.59000-0.59131 \mu_{\mathrm{N}}$. It appears that the old value of the shielding constant, $17810 \mathrm{ppm},{ }^{6}$ used to determine the literature value of $\mu\left({ }^{207} \mathrm{~Pb}\right), 0.592583 \mu_{\mathrm{N}}$, was too large (this old value of the shielding constant combined with our new experimental data leads to a similar result, $\left.0.59314 \mu_{\mathrm{N}}\right)$.

\section{Conclusions}

Following the theoretical calculations, we have assumed the ${ }^{207} \mathrm{~Pb}$ shielding of an isolated $\mathrm{Pb}\left(\mathrm{CH}_{3}\right)_{4}$ molecule to be $10790 \mathrm{ppm}$. This shielding constant corresponds to the experimental frequency measured for an isolated molecule; these values lead to a shielding scale for ${ }^{207} \mathrm{~Pb}$ NMR spectroscopy in which for liquid $\mathrm{Pb}\left(\mathrm{CH}_{3}\right)_{4}$ we obtain $\sigma(\mathrm{Pb})=10799.7 \mathrm{ppm}$. The fully hydrated $\mathrm{Pb}^{2+}$ ion has, according to our measurements, a much larger shielding of $13657.2 \mathrm{ppm}$.

The direct measurement of the shielding constant becomes possible once the magnetic moment of ${ }^{207} \mathrm{~Pb}$ has been established. ${ }^{14}$ Our new value for the ${ }^{207} \mathrm{~Pb}$ magnetic moment, obtained from $\mathrm{Pb}\left(\mathrm{CH}_{3}\right)_{4}$ gas-phase NMR and the corresponding ab initio calculations, is $0.0019 \mu_{\mathrm{N}}$ smaller than the old value determined from NMR data. This is consistent with our previous experience $^{11,12}$ - old literature values of magnetic moments determined from NMR are overestimated, because overestimated values of the NMR shielding have been used in their derivation (in the case of $\mathrm{Pb}^{2+}, 17800 \mathrm{ppm}$ instead of the more correct value of $13657.2 \mathrm{ppm})$.

\section{Acknowledgements}

This work was partly financed by the National Science Centre (Poland) grant, according to the decision No. DEC-2011/01/B/ ST4/06588 (B. A., W. M., and K. J.). A. A. acknowledges support from the projects APVV-15-0105 and VEGA 1/0279/16 and usage of the resources of HPC Cluster of Slovak University of Technology and Computing Centre of the Slovak Academy of Sciences (projects ITMS 26230120002 and 26210120002). T. B. D. and K. R. acknowledge the support of the Research Council of Norway through a Centre of Excellence Grant 
(Grant No. 179568/V30). Computer time from the Norwegian Supercomputing program NOTUR is also gratefully acknowledged (Grant No. NN4654K).

\section{References}

1 J. Mason, Multinuclear NMR, Plenum Press, New York, 1987.

2 R. K. Harris, E. D. Becker, S. M. C. de Menezes, R. Goodfellow and P. Granger, Pure Appl. Chem., 2001, 73, 1795-1818.

3 B. Wrackmeyer and K. Horchler, Annu. Rep. NMR Spectrosc., 1990, 22, 249-306.

4 B. Wrackmeyer, Annu. Rep. NMR Spectrosc., 2002, 47, 1-37.

5 N. J. Stone, At. Data Nucl. Data Tables, 2005, 90, 75-176.

6 O. Lutz and G. Stricker, Phys. Lett. A, 1971, 35, 397-398.

7 E. Cohen, T. Cvitaš, J. Frey, B. Holmström, K. Kuchitsu, R. Marquardt, I. Mills, F. Pavese, M. Quack, J. Stohner, H. Strauss, M. Takami and A. Thor, Quantities, Units and Symbols in Physical Chemistry, IUPAC Green Book, IUPAC \& RSC Publishing, Cambridge, 3rd edn, 2nd printing, 2008.

8 H. M. Gibbs and C. M. White, Phys. Rev., 1969, 188, 180-187.

9 G. Co', V. D. Donno, M. Anguiano, R. N. Bernard and A. M. Lallena, Phys. Rev. C: Nucl. Phys., 2015, 92, 024314.

10 J. Li, J. X. Wei, J. N. Hu, P. Ring and J. Meng, Phys. Rev. C: Nucl. Phys., 2013, 88, 064307.

11 M. Jaszuński and K. Jackowski, Lect. Notes Phys., Springer, 2008, vol. 745, pp. 233-260.

12 A. Antušek, K. Jackowski, M. Jaszuński, W. Makulski and M. Wilczek, Chem. Phys. Lett., 2005, 411, 111-116.

13 M. Jaszuński, A. Antušek, P. Garbacz, K. Jackowski, W. Makulski and M. Wilczek, Prog. Nucl. Magn. Reson. Spectrosc., 2012, 67, 49-63.

14 K. Jackowski, M. Jaszuński and M. Wilczek, J. Phys. Chem. A, 2010, 114, 2471-2475.

15 K. Jackowski and M. Jaszuński, Concepts Magn. Reson., Part A, 2007, 30, 246-260.

16 K. Jackowski, M. Wilczek, W. Makulski and W. Koźmiński, J. Phys. Chem. A, 2002, 106, 2829-2832.

17 K. Jackowski, J. Mol. Struct., 2006, 786, 215-219.

18 P. J. Mohr, B. N. Taylor and D. B. Newell, Rev. Mod. Phys., 2012, 84, 1527-1605.

19 N. Altounian, A. Glatfelter, S. Bai and C. Dybowski, J. Phys. Chem. B, 2000, 104, 4723-4725.

20 A. F. Maldonado and G. A. Aucar, J. Phys. Chem. A, 2014, 118, 7863-7875.

21 L. Visscher and K. G. Dyall, At. Data Nucl. Data Tables, 1997, 67, 207-224.

22 T. Oyamada, T. Iijima and M. Kimura, Bull. Chem. Soc. Jpn., 1971, 44, 2638-2642.

23 J. Gauss and J. F. Stanton, J. Chem. Phys., 1995, 102, 251-253.

24 J. Gauss and J. F. Stanton, J. Chem. Phys., 1996, 104, 2574-2583.

25 J. Gauss, J. Chem. Phys., 2002, 116, 4773-4776.
26 M. Kállay and J. Gauss, J. Chem. Phys., 2004, 120, 6841-6848. 27 CFOUR, a quantum chemical program package written by J. F. Stanton, J. Gauss, M. E. Harding, P. G. Szalay with contributions from A. A. Auer, R. J. Bartlett, U. Benedikt, C. Berger, D. E. Bernholdt, J. Bomble, L. Cheng, O. Christiansen, M. Heckert, O. Heun, C. Huber, T.-C. Jagau, D. Jonsson, J. Jusélius, K. Klein, W. J. Lauderdale, D. A. Matthews, T. Metzroth, L. A. Mück, D. P. O'Neill, D. R. Price, E. Prochnow, C. Puzzarini, K. Ruud, F. Schiffmann, W. Schwalbach, C. Simmons, S. Stopkowicz, A. Tajti, J. Vázquez, F. Wang, J. D. Watts and the integral packages MOLECULE (J. Almlöf and P. R. Taylor), PROPS (P. R. Taylor), ABACUS (T. Helgaker, H. J. Aa. Jensen, P. Jørgensen, and J. Olsen), and ECP routines by A. V. Mitin and C. van Wüllen. For the current version, see http://www.cfour.de.

28 F. London, J. Phys. Radium, 1937, 8, 397-409.

29 K. Wolinski, J. F. Hinton and P. Pulay, J. Am. Chem. Soc., 1990, 112, 8251-8260.

30 K. G. Dyall, Theor. Chem. Acc., 1998, 99, 366-371.

31 K. G. Dyall, Theor. Chem. Acc., 2002, 108, 335-340.

32 K. G. Dyall, Theor. Chem. Acc., 2006, 115, 441-447.

33 K. G. Dyall, Unpublished Basis Sets for 2p-3p Elements, Available from the Dirac web site, http://dirac.chem.sdu.dk.

34 A. C. Neto and F. E. Jorge, Chem. Phys. Lett., 2013, 582, 158-162.

35 ReSpect, version 3.4.0 (2014) - Relativistic Spectroscopy DFT program of authors, S. Komorovsky, M. Repisky, V. G. Malkin, O. L. Malkina, M. Kaupp, K. Ruud, with contributions from, R. Bast, U. Ekström, M. Kadek, S. Knecht, L. Konecny, I. Malkin-Ondik, E. Malkin, See http://www. respectprogram.org, accessed Mar 15, 2016.

36 S. Komorovsky, M. Repisky, O. L. Malkina, V. G. Malkin, I. Malkin Ondik and M. Kaupp, J. Chem. Phys., 2008, 128, 104101.

37 S. Komorovsky, M. Repisky, O. L. Malkina and V. G. Malkin, J. Chem. Phys., 2010, 132, 154101.

38 S. Komorovsky, M. Repisky, E. Malkin, T. B. Demissie and K. Ruud, J. Chem. Theory Comput., 2015, 11, 3729-3739.

39 A. D. Becke, Phys. Rev. A: At., Mol., Opt. Phys., 1988, 38, 3098-3100.

40 J. P. Perdew, Phys. Rev. B: Condens. Matter Mater. Phys., 1986, 33, 8822-8824.

41 J. P. Perdew, K. Burke and M. Ernzerhof, Phys. Rev. Lett., 1996, 77, 3865-3868.

42 A. D. Becke, J. Chem. Phys., 1993, 98, 5648-5652.

43 C. Lee, W. Yang and R. G. Parr, Phys. Rev. B: Condens. Matter Mater. Phys., 1988, 37, 785-789.

44 P. J. Stephens, F. J. Devlin, C. F. Chabalowski and M. J. Frisch, J. Phys. Chem., 1994, 98, 11623.

45 K. McQuinn, F. Hof, J. S. McIndoe, X. Chen, G. Wu and A. J. Stace, Chem. Commun., 2009, 4088-4090.

46 I. Persson, Pure Appl. Chem., 2010, 82, 1901-1917.

47 A. Bhattacharjee, T. S. Hofer, A. B. Pribil, B. R. Randolf, L. H. V. Lim, A. F. Lichtenberger and B. M. Rode, J. Phys. Chem. B, 2009, 113, 13007-13013. 
48 K. A. Peterson, J. Chem. Phys., 2003, 119, 11099-11112.

49 K. A. Peterson, D. Figgen, E. Goll, H. Stoll and M. Dolg, J. Chem. Phys., 2003, 119, 11113-11123.

50 T. H. Dunning Jr., J. Chem. Phys., 1989, 90, 1007-1023.

51 M. Valiev, E. J. Bylaska, N. Govind, K. Kowalski, T. P. Straatsma, H. J. J. van Dam, D. Wang, J. Nieplocha,
E. Apra, T. L. Windus and W. A. de Jong, Comput. Phys. Commun., 2010, 181, 1477-1489.

52 B. O. Roos, R. Lindh, P.-Å. Malmqvist, V. Veryazov and P.-O. Widmark, J. Phys. Chem. A, 2004, 108, 2851-2858.

53 A. Antušek and F. Holka, J. Chem. Phys., 2015, 143, 074301. 